Contents list available at IJRED website

Int. Journal of Renewable Energy Development (IJRED)

Journal homepage: www.ijred.com

\title{
Enhancement of Energy Efficiency and Food Product Quality Using Adsorption Dryer with Zeolite
}

\author{
M. Djaeni*a, S.B. Sasongko a and A.J.B. van Boxtel ${ }^{b}$ \\ a Department of Chemical Engineering Faculty of Engineering, Diponegoro University, Jl Prof H. Soedharto, Tembalang, Semarang, INDONESIA \\ b System and Control Group, Agrotechnology and Food Science, Wageningen University, Bornsesteg 59, 6708 PD Wageningen, THE NETHERLANDS
}

\section{Article history:}

Received February 13, 2013

Received in revised form February 26, 2013 Accepted April 4, 2013

Available online

\begin{abstract}
Drying is a basic operation in wood, food, pharmaceutical and chemical industry. Currently, several drying methods are often not efficient in terms of energy consumption (energy efficiency of 20-60\%) and have an impact on product quality degradation due to the introduction of operational temperature upper $80^{\circ} \mathrm{C}$. This work discusses the development of adsorption drying with zeolite to improve the energy efficiency as well as product quality. In this process, air as drying medium is dehumidified by zeolite. As a result humidity of air can be reduced up to $0.1 \mathrm{ppm}$. So, for heat sensitive products, the drying process can be performed in low or medium temperature with high driving force. The study has been conducted in three steps: designing the dryer, performing laboratory scale equipment (tray, spray, and fluidised bed dryers with zeolite), and evaluating the dryer performance based on energy efficiency and product quality. Results showed that the energy efficiency of drying process is $15-20 \%$ higher than that of conventional dryer. In additon, the dryer can speed up drying time as well as retaining product quality.
\end{abstract}

Keywords: adsorption, drying, energy efficiency, zeolite, heat sensitive

\section{Introduction}

Drying is a basic operation in wood, food, pharmaceutical and chemical industry. The operation is important to enhance the preservation properties of agriculture crops and pharmaceutical products, to reduce the costs for transportation, and to increase customer convenience of food products. An example is milk powder that can be stored for a period longer than a year instead of some weeks (Birchal et al. 2005) and for which the transportation volume is 8-10 times reduced. Nowadays, the importance of powdered food products as for example soups, sauces and dried yeasts is increasing for consumer convenience.

A large part of the total energy usage in industry is spent in drying. For example $70 \%$ of total energy spent in the production of wood products, $50 \%$ of textile fabrics, $27 \%$ of paper, $33 \%$ of pulp production is used for drying (Kudra 2004). In food and pharmaceutical industry the energy consumption for drying is around $15 \%$ of the total energy usage in this sector. Energy spent for drying varies between countries and ranges between $15-20 \%$ of the total energy consumption in industry (Gilmour et al. 2004).

Currently several drying methods are used, ranging from traditional to modern processing: e.g. direct sun drying, convective drying, microwave and infra-red drying, freeze and vacuum drying. However, the current drying technology is often not efficient in terms of energy consumption (energy efficiency of 20-60\%) and has a high environmental impact due to combustion of fossil fuel or wood as energy source (Gilmour et al. 2004). The sources of fossil fuel are limited, the price of energy increases, the world wide industrial energy usage rises, and increase of greenhouse gas emission becomes a global issue due to climate change; the need for a sustainable industrial development with low capital and running cost especially for energy becomes

\footnotetext{
* Corresponding author:

Email : m.djaeni@undip.ac.id; mzaini98@yahoo.com
} 
more and more important. In this context the development of efficient drying methods with low energy consumption is an important issue for research in drying technology.

A large range of drying methods is being applied by small and industrial users. Next consideration is just a limited review on some major drying methods. Direct sun drying is simple and doesn't need fuel fossil for energy generation, but the system needs a large drying area, long drying time (often 3-5 days), high operational cost for labour, and depends highly on the climate. Furthermore, product contamination may occur due to the open air conditions and therefore sun dried food products are not accessible for all markets. Improvement of this drier type has been achieved by using for example a solar tunnel drier equipped with an electric fan to dry chilli (Mastekbayeva 1998). Although, the result showed that the processing time is reduced, it is still rather long (2-3 days).

Convective drying (Kiranoudis 1996) is more attractive than sun drying because of the shorter operational time, low product contamination, lower operational costs, no dependency on the climate, and relative limited space usage. However, the disadvantage of this system is that the product quality can be affected by the operational temperature, and the high energy consumption.

Vacuum and freeze drying systems are operated in the temperature range -20 to $-0^{\circ} \mathrm{C}$ and for pressures in the range of 0.0006 to $0.006 \mathrm{~atm}$ (Ocansey 1988; Hu et al. 1998). These systems are useful for the production of high quality, high value products with minimizing flavour loss and degradation reactions (e.g. protein denaturation, browning and enzymatic reactions (Boss et al. 2004))). However, $\mathrm{Hu}$ et al showed the vacuum freeze- dryer is high energy consumption, investment costs, and long drying time (Hu et al. 1998).

Considerable amounts of energy are lost in the offgas of convective drying systems. The off-gas temperatures are commonly in the range $60-90^{\circ} \mathrm{C}$ but may even rise till $120^{\circ} \mathrm{C}$ as reported for spray drying of Roselle extracts (Andrade \& Flores 2004) and sugarrich food products. Until now, off-gas flows with these temperatures are hardly recovered for use in other processes. As a result, the energy efficiency of drying is poor. The energy equivalent of about $1.5 \mathrm{~kg}$ of steam to remove $1 \mathrm{~kg}$ of water (i.e. 65\% energy efficiency) is common for spray drying, and for low temperature drying of heat sensitive products (food and medicines) the required amount of energy exceeds $2 \mathrm{~kg}$ steam for 1 $\mathrm{kg}$ water removal (i.e. below 50\% energy efficiency).

Innovation and research in drying technology during the last decades resulted in reasonable improvements, but breakthrough solutions with respect to the energy efficiency are scarce. Therefore it can be noted that innovation in drying technology tends to reach a saturation level and a further significant reduction in energy consumption seems not feasible (Kudra \&
Mujumdar 2002). Positive results were obtained in adsorption dryer with zeolite to speed up drying rate and to improve energy efficiency, while other new developed drying processes cannot compete with traditional drying method in terms of energy efficiency and operational cost (Revilla et al. 2006; Djaeni et al. 2007a).

This paper presents the development of adsorption drying with zeolite to improve energy efficiency. The work focuses to discusse the conceptual design of adsorption dryer with zeolite, the energy efficiency of the drying with zeolite, and case study of zeolite application for carrageenan, paddy, and corn.

\section{Methodology}

To answer the questions, the research was conducted as illustrated in Fig. 1. The methods was started by identifying the current problem in drying application. After that, the conceptual design of adsorption dryer with zeolite was formulated. In this methods, air as drying medium was dehumidified by zeolite that allows efficient process at low or medium temperature. To prove the concept, the mathematical modelling for steady-state as well as dynamic involving one and two dimensional models with mass and heat transport have been simulated (Djaeni et al. 2007b; Djaeni et al. 2009).

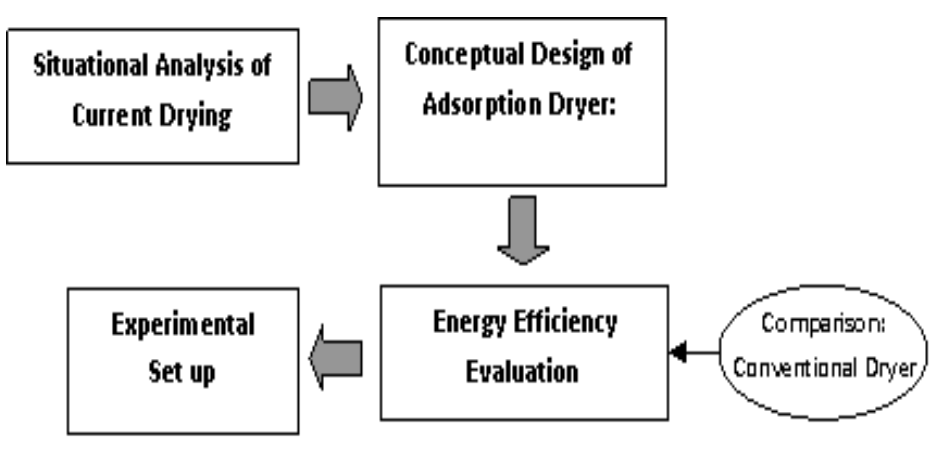

Fig. 1 Schematic Diagram of Research

\subsection{Conceptual Design}

The principle of zeolite drying was based on the removal of the water from the fresh air before feeding to the dryer. At the same time the air was preheated due to the release of adsorption heat. As a result of these effects the driving force for drying was enhanced, the required energy is reduced, and also a reduction of drying temperature is possible.

The disadvantage of zeolite drying was the high energy consumption and the high temperature needed in the regenerator to release the water from the saturated zeolite. It limits the improvement of the overall energy efficiency. For example, the release of 1 
$\mathrm{kg}$ of water from a zeolite type $13 \mathrm{X}$, required $3200 \mathrm{~kJ}$ (Djaeni et al. 2007b).

A promising alternative to improve the energy efficiency was the application of pinch technology for energy recovery system. Hence, the energy from off gas exiting regenerator can be used to pre-heat either air before entering or air for regenerating zeolite. In this case, a number of heat exchanger network was required.

Multistage zeolite drying has potential for further improvement of the energy efficiency. In such system product was dried in a number of succeeding stages (see Fig. 2). The product in the first stage was dried with air dehumidified by zeolite. After passing an adsorber bed with zeolite, the exhaust air from this stage was reused for product drying in a next stage. This concept was repeated several times. The system can be operated as a co-current, counter-current or crosscurrent system. The main benefit of the system was that the energy content of the exhaust air is reused several times. Moreover, the released adsorption heat was utilized for drying in the succeeding stages. As a consequence, product drying hardly requires heat supply. The required heat for the regeneration of zeolite was kept low by pinch technology based heat recovery (Djaeni et al. 2007b; Djaeni et al. 2009).

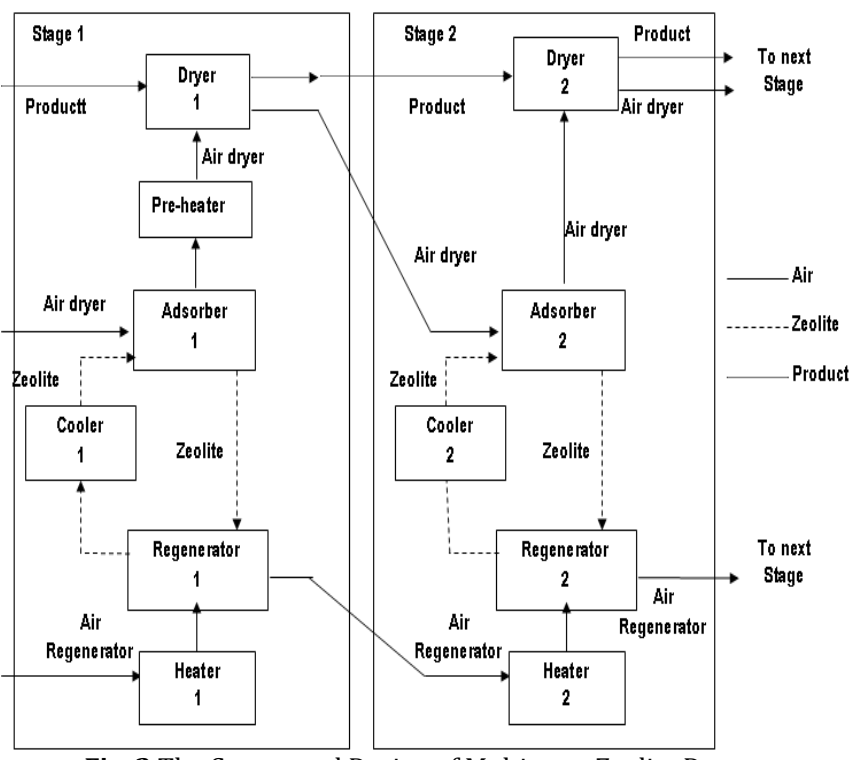

Fig. 2 The Conceptual Design of Multistage Zeolite Dryer

\subsection{Energy Efficiency calculation}

The energy efficiency from both the models were estimated based on the mass and the heat balance. The results were also compared with the conventional dryer without zeolite. In overall, the total of energy efficiency was estimated as follows (Djaeni et al. 2007a; Djaeni et al. 2007b):

$$
\eta=100 \%\left(\frac{Q_{\text {evap }}}{Q_{\text {int } \text { rod }}}\right)
$$

Where, $\eta$ is the total energy efficiency (\%), $Q_{\text {introd }}$ is the total heat required in the system $\left(\mathrm{kJ} \cdot \mathrm{h}^{-1}\right)$, and $Q_{\text {evap }}$ is the total heat used for evaporating water in the dryer $\left(\mathrm{kJ} \cdot \mathrm{h}^{-1}\right)$.

$Q_{\text {introd }}$ can be estimated based on the total heat required for heating air to dryer, air for regerating saturated zeolite, and the heat that can be recyled from exhaust air, as expressed in equation 2 (Djaeni et al. 2007a; Djaeni et al. 2007b).

$$
Q_{\text {introd }}=Q_{h, a}+Q_{\text {reg }}-Q_{\text {rec }}
$$

Here, $Q_{h, a}$ is the total heat to heat up air for dryer (kJ.h-1), $Q_{\text {reg }}$ is heat to regenerate saturated zeolite (kJ.h-1), and $Q_{\text {rec }}$ is the total heat recycled from exhaust air exiting from regerenator and dryer $\left(\mathrm{kJ} \cdot \mathrm{h}^{-1}\right)$.

Meanwhile, corresponds to (Djaeni et al. 2007a; Djaeni et al. 2007b):

$$
Q_{\text {evap }}=F_{p}\left(q_{w, 0}-q_{w, f}\right) \lambda
$$

$F_{p}$ is flow of dry product entering dryer (kg.h-1), $\lambda$ is the latent heat of water evaporation ( $\left.\mathrm{kJ} . \mathrm{kg}^{-1}\right), q_{w, 0}$ is the moisture in product entering dryer ( $\mathrm{kg}$ water per $\mathrm{kg}$ dry product), and $q_{w, f}$ is the moisture in product exiting the dryer (kg water per kg dry product).

\subsection{Performing Experimental Work}

The second step involve the experimental method for testing the adsorption dryer performance using product immitation such as sponge (Djaeni et al. 2007b; Djaeni et al. 2009). After that, the real food product namely carrageenan, corn, and rice were also tested in adsorption dryer (Djaeni et al. 2012; Djaeni \& van Boxtel 2012; Djaeni et al. 2013). In carrageenan, the air was dehumidified in separated column (Djaeni et al. 2012a). The air was then used for drying (see Fig. 3).

The carrageeenan drying were performed in a tray dryer equipped with a unit for air dehumidification with zeolite (see figure 3 for a schematic view) (Djaeni et al. 2012). Ambient air with relative humidity (RH) between $70-80 \%$ and temperature between $29-33^{\circ} \mathrm{C}$ passed the adsorber column (suppose A) which contains the activated natural zeolite $(1.5 \mathrm{~kg} /$ column, particle size $2 \mathrm{~mm}$ ). About $70-80 \%$ of water in air is removed, and the air temperature increases $5-10^{\circ} \mathrm{C}$ due to the release of adsorption heat. Next, the dehumidified air was heated to the chosen drying temperature. The hot air was fed to the dryer where water evaporates from the wet carrageenan sheets with initial water content of $82 \%$. For the standard experiments carrageenan sheets with $2 \mathrm{~mm}$ thickness and $6 \times 6 \mathrm{~cm}$ were used. When the zeolite approaches saturation the 
adsorption function was switched to column $\mathrm{B}$ and zeolite in column A was regenerated at $200^{\circ} \mathrm{C}$.

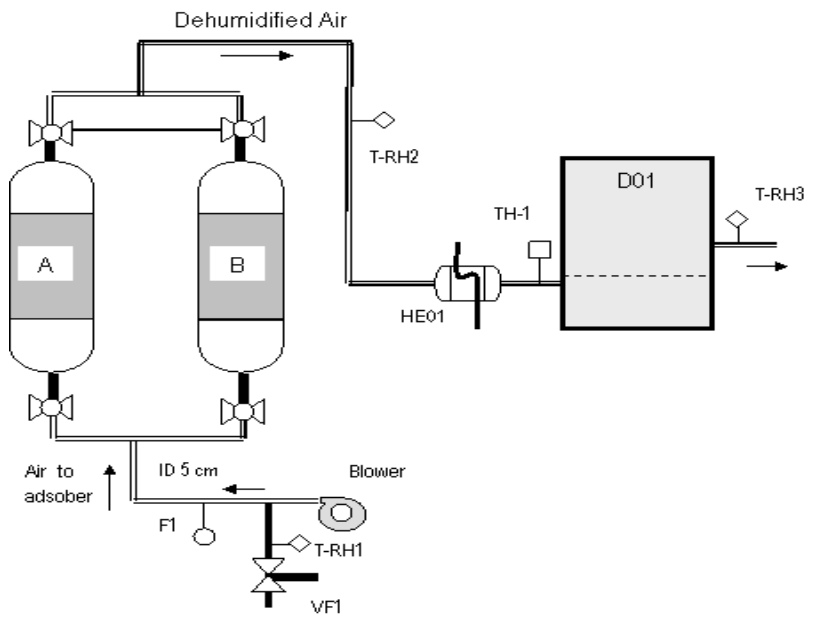

Fig. 3 Schematic overview of the experimental equipment. Internal diameter of columns $A$ and $B$ is $0.12 \mathrm{~m}$, diameter of piping is $0.05 \mathrm{~m}$, tray dryer size 0.40x0.25x0.60 m (Djaeni et al. 2012a).

Meanwhile, for the corn and paddy, the design was a bit different where the corn or paddy as a product and zeolite was mixed in certain composition and placed in a column. The mixture was fluidized by air at different temperature. Air will evaporate water from the product, while the vapor will be adsorbed by zeolite. Hence, the de-sorption (drying) and adsorption take place simultaneously (see Fig. 4). The advantages, is the driving force for drying can be kept high until zeolite saturated by water (Djaeni \& van Boxtel 2012; Djaeni et al. 2013). For initial test, the zeolite 3A from Zeochem, Switzerland and natural zeolite activated by $\mathrm{KOH}$ were used and compared with drying without adsorbent.

\section{Results}

\subsection{Energy efficiency based on conceptual design}

Table 1 presents the results for the single and multi stage adsorption drying systems indicating that the energy efficiency of adsorption dryer is higher than that of conventional dryer. For all cases, extending the number of stage increased the efficiency.

Tabel 1.

Energy Efficiency of Adsorption Dryers

\begin{tabular}{ccc}
\hline Options & $\begin{array}{c}\text { Number of } \\
\text { stages }\end{array}$ & Energy efficiency (\%) \\
\hline $\begin{array}{c}\text { Conventional } \\
\text { dryer }\end{array}$ & 1 & 60 \\
\hline Single stage & 1 & 72 \\
Cross-current & 2 & 81 \\
Co-current & 3 & 83 \\
& 4 & 84 \\
& 2 & 78 \\
& 3 & 82 \\
Counter-current & 4 & 82 \\
& 2 & 80 \\
& 3 & 88 \\
& 4 & 90 \\
\hline
\end{tabular}

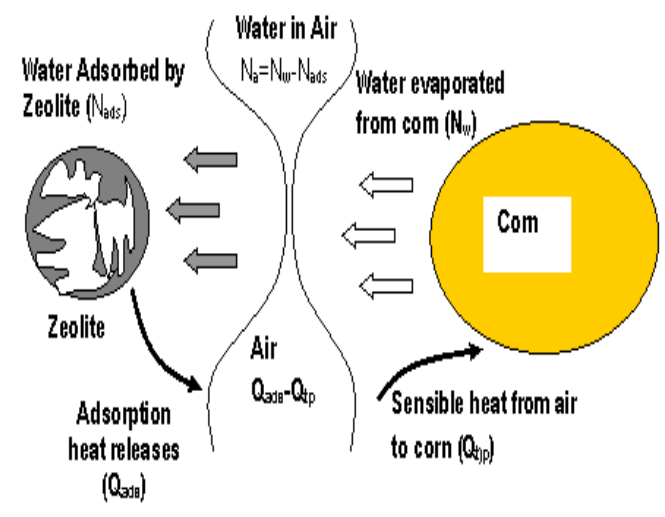

(a)

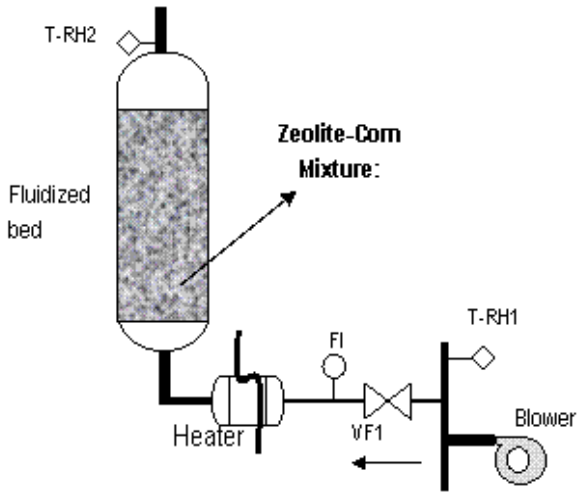

$\mathrm{T}-\mathrm{RH}=$ humidity temperature measure $\mathrm{FI}=$ flow meter, $\mathrm{VF} 1=$ value

(b)

Fig. 4 Mixed-adsorption dryer with zeolite (a. process transport, b. operational system) 
Multistage zeolite drying systems with 2,3 or 4 stages have been configured and evaluated in combination with a heat exchanger network for heat recovery. Calculation results obtained from a steadystate model based on overall mass and heat balances, showed that the energy efficiency of a multistage system was significantly higher than that of conventional drying systems and single-stage zeolite drying systems. The efficiency increased with the number of stages, but a multistage system with 3 stages were the most effective. Above this number the energy efficiency improvement was marginal and probably not sufficient to justify the increase of system complexity.

The counter-current dryer was the most efficient process and achieves an energy efficiency of $88 \%$ for a 3-stage system. In the counter-current dryer, the air and product flows were in the opposite direction; fresh product was contacted with the air in the last stage of adsorbers. The advantage of this system was the ability to use the air from last stage to preheat fresh product. Furthermore, heat and mass transfer in each stage was enhanced which is reflected by the enhanced energy efficiency (Djaeni et al. 2007b).

\subsection{Energy efficiency based on experiment}

The experiment was conducted to prove the concept. Initially, the adsorption dryer with zeolite was constructed in single stage system with adsorptionregeneration working in shift. The results showed the energy efficiency was close to that of the concept. The energy efficiency increased corresponding to the increase of the ratio between the air flow for drying and air flow for regeneration. At a ratio 4:1 the efficiency was $70-72 \%$ which was similar to the calculations results in the previous study using a steady-state model (Djaeni et al. 2009).

The shift time of adsorption-regeneration also affected the energy efficiency. In this work, the best performance was obtained for shift time 60 minutes. Main reason is that for a shorter shifting time, the zeolite was not sufficiently regenerated, which lowered the efficiency of the zeolite for air dehumidification during operational time (Djaeni et al. 2009).

\subsection{Drying Time and Prodcut Quality Aspects}

The comparison of drying time on dryer with and without zeolite has been conducted for food products such as corn, carrageenan, and paddy (Djaeni et al. 2012; Djaeni \& van Boxtel 2012; Djaeni et al. 2013). In carrageenan, for operational temperature $80^{\circ} \mathrm{C}$ or below, the adsorption dryer with zeolite can speed up drying time 50 - 60 minutes shorter than that of without zeolite (Djaeni et al. 2012). Meanwhile, for corn and paddy, the dryer with zeolite shortened drying time about 70 minutes (Djaeni \& van Boxtel 2012; Djaeni et al. 2013). The other positive effect also indicated in drying seed and corn pointed in Revilla et al (2006) and Alikhan et al (1992) (Alikhan et al. 1992; Revilla et al. 2006).

Meanwhile, the corn and paddy quality measured in protein and starch content did not degrade during the process at various zeolite composition in mixture (Djaeni \& van Boxtel 2012; Djaeni et al. 2013). Moreover, in carrageenan the product whiteness and gel strength can be retained within industrial standard food application (Djaeni \& van Boxtel 2012; Djaeni et al. 2013). These positive results are comparable with controlable adsorption dryer for cabbage, egg plants, and carrot, performed by Nagaya et al (2006) (Nagaya et al. 2006). So, the dryer with zeolite can compete with the other low temperature methods (freeze and adsorption dryer) (Ratti 2001). Even, the zeolite is better since the air dehumidification was superior as well as higher driving force for drying (Kim et al. 2007).

\section{Conclusions}

Two approaches involving conceptual design and experimental set up steps have been conducted to realize adsorption dryer with for improving energy efficiency. All results indicated the same energy efficiency improvement where the best results are obtained for a ratio between the air flow for drying and the air flow for regeneration 4:1. The positive results will boost the development of novel dryers for efficient energy usage and retaining product quality for industrial application.

The works also confirm that the adsorption dryer with zeolite is potential for heat sensitive food product in term of product quality and drying rate aspects. With the adsorption dryer by zeolite, the physicho-chemical product properties can be well retained. Beside that, the drying time can be halved.

\section{Acknowledgement}

This research was conducted at System and Control Group, Agrotechnology and Food Science Wageningen University, and Laboratory of Process Engineering, Department of Chemical Engineering, Faculty of Engineering, Diponegoro University.

\section{References}

Alikhan, Z., Raghavan, G.S.V., Mujumdar, A.S. (1992) Adsorption drying of corn in zeolite granules using a rotary drum. Drying Technology 10(3): 783-797

Andrade, I., Flores, H. (2004) Optimization of spray drying roselle extract (Hibiscus sabdariffa 1.). Proceedings of the 14th 
International Drying Symposium (IDS 2004), Sao Paulo Brazil, 2225 August 2004 A:597-604

Birchal, V.S., Passos, M.L., Wildhagen, G.R.S., Mujumdar, A.S. (2005) Effect of spray-dryer operating variables on the whole milk powder quality. Drying Technology 23(3): 611-636

Boss, E.A., Costa, N.A., Rubens, M.F., Eduardo, C.V.D. (2004) Freeze drying process: Mathematical model and simulation. Proceedings of the 14th International Drying Symposium (IDS 2004), Sao Paulo, Brazil, 22-25 August 2004; A: 477-484

Djaeni, M., Bartels, P., Sanders, J., van Straten, G., van Boxtel, A.J.B. (2007a) Process integration for food drying with air dehumidified by zeolites. Drying Technology 25 (1): 225-239

Djaeni, M., Bartels, P.V., Sanders, J.P.M.; van Straten, G., van Boxtel, A.J.B. (2007b) Multistage zeolite drying to enhance energy efficiency of Food Drying.Drying Technology, 25 (6): 1053-1067

Djaeni, M., Bartels, P.V., van Asselt, C.J., Sanders, J.P.M., van Straten, G., van Boxtel, A.J.B. (2009) Assessment of a two-stage zeolite dryer for energy efficient drying. Drying Technology 27(10): 1205-1216

Djaeni, M., Sasongko, S.B., Prasetyaningrum, A., Jin, X., and van Boxtel, A.J.B. (2012) Carrageenan drying with dehumidified air: drying characteristics and product quality. International Journal of Food Engineering 8(3), Article 32. DOI: 10.1515/1556-3758.2682

Djaeni, M., van Boxtel, A.J.B. (2012) Development of a novel energyefficient adsorption dryer with zeolite for food products. The 2nd International Symposium on Processing \& Drying of Foods, Vegetables and Fruits (ISPDFVF 2012), University of Nottingham, Malaysia Campus, 18th - 19th June 2012

Djaeni, M., Ayuningtyas, D., Aishah, N., Hargono, H. (2013) paddy drying in mixed adsorption dryer with zeolite: Drying Rate and Time Estimation. Submitted to Reaktor 2013

Gilmour, J.E., Oliver, T.N., Jay, S. (2004) Energy use for drying process: The potential benefits of airless drying. In: Energy aspects in drying; Kudra T. Drying Technology 22(5): 917-932
Hu, X., Zhang, Y., Hu, C., Tao, M., Chen, S. (1998) A comparison of methods for drying seeds: vacuum freeze-drier versus silica gel. Seed Science Research 8, paper 7

Kim, K.R., Lee, M.S., Paek, S., Yim, S.P., Ahn, D.H., Chung, H. (2007) Adsorption tests of water vapor on synthetic zeolites for an atmospheric detritiation dryer. Radiation Physics and Chemistry 76: 1493-1496

Kiranoudis, C.T., Maroulis Z.B., Marinos-Kouris D. (1996) Drying of solids: Selection of some continuous operation dryer types. Computer \& Chem. Eng. 20, Supplement 1, S177-182

Kudra,T., Mujumdar, A.S. (2002) Advanced Drying Technology. Marcel Dekker Inc., New York, USA

Kudra, T. (2004) Energy aspects in drying. Drying Technology 22(5): 917-932

Nagaya, K., Li, Y., Jin, Z., Fukumuro, M., Ando, Y., Akaishi, A. (2006) Low-temperature desiccant-based food drying system with air flow and temperature control. Journal of Food Engineering 75:7177

Mastekbayeva, G.A., Leon, M.A., Kumar, S. (1998) Performance evaluation of a solar tunnel dryer for chilli drying. ASEAN Seminar and Workshop on Drying Technology, Bangkok, Thailand; 3-5 June 1998

Ocansey, O.B. (1988) Freeze-drying in a fluidized-bed atmospheric dryer and in a vacuum dryer: Evaluation of external transfer coefficients. Journal of Food Engineering 7(2): 127-146

Ratti, C. (2001) Hot air and freeze-drying of high-value foods: a review. Journal of Food Engineering 49: 311-319

Revilla, G.O., Velázquez, T.G., Cortés, S.L., Cárdenas, S.A. (2006) Immersion drying of wheat using Al-PILC, zeolite, clay, and sand as particulate media. Drying Technology 24(8): 1033-1038 